hundred songs, which are recorded and analysed in the present volume. It will thus be seen that the tribe possesses a very elaborate system of folk-songs, mostly associated each with a particular object, and it is to be noted with interest that, with the advent of civilising influences, phonographs have become much sought after by the Sioux themselves.

The distinctly tribal life of the Teton Sioux practically ceased with the suppression of the Sun Dance, the last of which was held in $188 \mathrm{I}$, the final buffalo hunts occurring in the two following years. The sun dance was a most elaborate religious ceremony, in which the sun symbolised the Divine Power. It lasted several days, and, besides the complex ritual involved in the raising of the Sacred Pole and other observances, the leading feature was the self-infliction of bodily torture by the participants as a sacrifice to their deity. In the most severe forms this involved suspending the bodies of the willing victims by slsewers and thongs driven through their flesh in the fierce heat of the sun until the victims tore themselves down, lacerating their flesh in the process. In addition, the whole of the assembly would go without food and drink for several days during this period. Each phase of the ritual had its special song. The natives even now deplore the substitution of the white man's religion and education for what they regarded as a discipline in heroism and bravery. It is stated that boys used to go through a miniature copy of the ritual in which they aspired to participate when of adult age.

Another group of songs is associated with certain societies existing in the tribe. Some of these, called Dream Societies, are constituted of individuals who are distinguished by the particular animals which appeared to them in dreams, such as the badger, buffalo, or elk; others were of a military character.

The only musical instrument which figures in most of these songs was the drum, which was of the usual type, but in the sun dance a stiff rawhide was also beaten. The author also refers very briefly to two whistles, one of bone used in the sun dance, the other of wood used in grass dances, which latter is capable of emitting a series of harmonics.

The tone-scale of the songs approximates to the well-known five-tone scale represented by the black keys of the piano, but the intervals are in reality a little different. A noticeable feature is a more or less marked resemblance to some of our present "modern" music, both in the absence of well-defined melody and in the irregularity of the rhythm. A few of the songs, indeed, do appear to possess something in the nature of a tune in them; in others the sequence of notes is very much of the same chaotic character that is so conspicuous at modern recitals. Again, in the rhythm one bar is often in three-time and the next in four-an artifice which Brahms knew how to use with good effect, but which is now commonly employed in order to render music unlovely, and therefore what is described as "thrilling." Again, the voice part is frequently independent of the drum rhythm, the latter being usually in more regular time. It might thus be Dossible that if suitable harmonics, or rather discords, were arded, these songs might appeal to the class of present-day concert-goers who appreciate the attempts of modern pian'sts to represent "Le Raid des Zéppelins."

What, however. is much more important is the glimpse which this unique collection affords of the highlv complex system of primitive poetic and musical art that this tribe of American Indians had built up, which is fast becoming obsolete under the social and educational influences brought into force by the white races.

G. H. BRYAN.

\section{ELECTRICAL PURIFICATION OF CLAYS}

$T \mathrm{HE}$ phenomena known as electrical endosmose and cataphoresis, whereby matter in a very finely divided or colloidal state is capable of being influenced by an electrical potential, have been extensively investigated. For instance, when a colloidal solution of arsenious sulphide is placed in a cell and a direct current at a potential of roo volts passed from suitable electrodes through the solution, the colloidal particles tend after a time to collect round the positive pole, leaving a clear zone round the negative pole.

It is found that rearly all substances, if is a sufficiently fine state of division, are attracted either to one pole or the other. It has also been observed that aggregates of certain fine particles can be dispersed and separated by adding to the fluid in which they are suspended minute quantities of alkali in the case of those particles attracted to the positive pole, and of acid to those which are attracted to the negative pole. Moreover, if the particles are not sufficiently susceptible to the dispersive effect of the added electrolyte, they can be made so by being allowed to adsorb some colloid, such as colloidal silicic acid.

This latter discovery has a most important bearing on the clay industry. China clay and ball clay are examples of such aggregates of fine farticles, and if a thick slip is made up of the clay and water the addition of small amounts of alkali causes the clay particles to disperse, and the slip, as a consequence, to become much thinner and more mobile, the clay particles remainin o in suspension a considerable time and exhibiting vigorous Brownian movement. On passing a current of electricity through such a suspension, the clay particles collect and adhere closely to the anode plate, the water collecting in a zone, substantially free from clay, round the cathode. Impurities in the original clay, such as mica, quartz, felspar, and iron compounds, are either unaffected by the electrical potential and settle out, or attracted to the cathode. A means of purifying clay on a commercial scale can thus be evolved from a consideration of the above phenomena, as was shown by the exhibit of raw and purified clays of the Osmosis Co., Ltd., at the recent British Scientific Products Exhibition.

The commercial equipment for such a process consists of a blunger, settling tanks to allow the coarse impurities to settle out of the suspension, and an Osmosis machine composed of a rectangular trough in which is arranged horizontally a cylindrical metal anode surrounded beneath the surface of the slip and at a short distance away from it by a cathode through which, by paddles or other means of circulation, the clay slip is driven. The cylinder is made to revolve slowly, and by means of a scraper the dried purified clay, containing $20-30$ per cent. of water, is collectẹd.

The machine not merely collects the suspended clay and frees it from water. but subjects the suspension to an electrical purification as well, for should there still be in suspension with the clay minute particles of mica, iron, and silica that have not had time to settle out in the tank, these are not attracted to the anode, but for the most part remain in the effluent leaving the trough. Consequently, electrically osmosed clav is a purer product than can be obtained by any method of settling or centrifuging.

The improvements effected by the process are:(I) Pyritic and other forms of uncombined iron are removed. (2) The sintering temperature of the clay is lowered so that a lower kiln-temperature can be emplnved, with consequent saving of fuel. (3) Clay can be graded ints different degrees of fineness. 
(4) Fireclays can be rendered more plastic and more refractory by this treatment.

Another very important application of cataphoresis is the electrical filter-press. In this press the electrical potential is utilised as a means of driving out the water from suspensions of fine particles; thus, instead of needing pressures running up to 20 atmospheres in some cases where ordinary filtration is used, a head of $14 \mathrm{ft}$. is ample for the purpose in the electrical filter-press. As an instance of the efficiency and speed with which filtering can be accomplished by such a press, a cake of china clay $4 \frac{1}{2}$ in. thick containing 25 per cent. of water can be made in less than two hours.

The applications of electrical endosmose or electrical dialysis in various industries is of importance. Gelatine can be freed from all inorganic mineral matter, so that an ashless gelatine can be obtained of a purity which should be suitable for photographic purposes. There is clear experimental evidence that pure colloidal silicic acid can be prepared from sodium silicate and alumina from sodium aluminate by subjecting their solutions to an electrical potential in cells with suitable diaphragms through which the alkali can migrate. These are a few examples of useful developments, but it is evident that an increasing number of important commercial processes may be expected to arise out of the application of the principles underlying the above phenomena.

\section{EVOLUTION IN POTATO-BEETLES.1}

$\mathrm{D}^{2}$

. W. L. TOWER has continued his attack on the "evolution problem" by a further study of Chrysomelid beetles of the genus Leptinotarsa. $\mathrm{He}$ first gives an account of the material as it occurs in natural conditions; he then describes the emergence of new attributes and qualities, discovering the relation of these to old characters and their interaction when brought into combination or into competition with existing characters; and, thirdly, he has experimented in Nature, chiefly in the Arizona deserts, with the new forms to see how newly arisen characters, or their combination into specific forms, behave as they meet the conditions of the environment into which they are thrust by the processes of their origination. His most general result is the demonstration that the methods of evolution are heterogeneous, even in these beetles, but "the basis of all methods of change is found to be directly the product of the nature of the genetic factors of composition and their capacity for diverse modes of reaction, especially with factors of the environing complex. Purpose, utility, and kindred concepts have found no support, every change appearing as the chance mechanistic product of the reacting agents; while the product of the reaction either was able or not able to operate under the conditions of origination, so that survival is decided at once, and not after long and faltering trials.'

The characters of organisms are usefully grouped under three chief categories:-(I) The specific proper. ties or qualities which cannot be altered without change in the identity of the kind; (2) attributes belonging to and distinguishing members of the same species or kind from une another; and (3) conditions or "states of being or activity which can be changed or removed without altering the identity of the body or its kind in any way." The central problem of evolution is the origin of diversity or heterogeneity, and Dr. Tower distinguishes two main possibilities : "first, transmutation in the qualities" with subsequent adjustments in the attributes and conditions of

1 " The Mechanism of Evolution in Leptinotarsa." By William T,awrence Cower. (Publcation No. 263.) Pp. $340+19$ pls. +156 figs. (Carnegie Institution of Washington, I918.) organisms; and, second, diversity resulting from recombinations (metathesis)." The gametic constitution or hereditary make-up of the organism consists of a number of factors (neither "carriers" of anything, nor fixed units, nor necessarily substances, but agents or centres of activity which make certain results possible) and of a number of determiners which settle which of several possible reactions will come off. "In Nature there is constant and unlimited mixing of these factors and determiners in all kinds of combinations; but out of this complex of interacting agencies certain definite patterns always come, so that the net result is a rather stable population as far as the patterns presented in any given location. 'The heterogeneity presented, however, is not one of quantity nor of directions of departure, but is at least analogous to the diversity found in many chemical operations where nearly related compounds are easily transmuted into some other through the presence or absence of something whose presence determines a different configuration of the system, and whose absence permits of another and diverse arrangement." The pattern on the beetle's pronotum is, in its way, an intricate system, and the presence of certain form-determiners decides the type. Thus, if we generalise from the beetles, variation is not so much the origin of something distinctively new as a shuffling of the pre-existing cards. It is recombination or metathesis. "The phenomena must be viewed as purely physical in character and of chance occurrence, dependent upon chance gametic agents, combinations, and conditions present, as far as their appearance and frequency in Nature are concerned." But the system in question (or any analogous set of characters), "although complex and the product of many interacting agents, nevertheless acts as a unit in many reactions, passing through the operations of reproduction and crossing in its entirety, or at other times emerging from the reactions changed in relations and arrangements of the elemental simplest characters, indicating altered relations between the conditioning agents." But when the further question is asked how the populations of beetles in different locations have become different, Dr. Tower confesses his inability to give any answer. "I have most earnestly, in this investigation, in numerous instances made effort to certainly discover the productive agents of conditions found in Nature. . but in no instance thus far have I been able to attain to the desired end of a pronf of the actual cause of the conditions observed."

We have not found the memoir very easy to read (and our quotations will in part show why). We think that the author might have focused more clearly the new conclusions he has arrived at. But the volume is the outcome of laborious investigations and careful critical analysis; it is a fine example of the modern transition from plausible speculations to the verifiable experiments. We are not so sure as the author is that science is shut up to mechanistic formulation; and we should like to know how he comes to be so sure that his beetles have no purposes. We notice a few misprints like "Cuèrrot," but they have, no doubt, arisen mechanically.

\section{UNIVERSITY AND EDUCATIONAL INTELLIGENCE.}

MME. CURIE has been appointed professor of radiology in the Warsaw University.

A scholarship of the value of 1200 rupees has been given to the Madras Medical College by Lt.-Col. W. D. Smith for the benefit of students in chemistry and drugs.

NO. 2600, VOL. IO3] 